\title{
Outcomes of Mitral Valve Replacement after Closed Mitral Valvotomy: A Retrospective Cohort Study
}

\author{
Renjith Sreekantan, MCh, Bineesh K. Radhakrishnan, MCh, Varghese T. Panicker, MCh, \\ Jayakumar Karunakaran, $\mathrm{MCh}$ \\ Cardiovascular and Thoracic Surgery Department, Sree Chitra Tirunal Institute for Medical Sciences and Technology, \\ Thiruvananthapuram, Kerala, India
}

\section{ABSTRACT}

Background: The incidence of rheumatic fever and rheumatic heart disease still remains high in the developing countries. Mitral stenosis is predominantly due to rheumatic origin and affects females more than males. Historically, closed mitral valvotomy (CMV) was the first effective intervention for mitral stenosis. We studied the immediate and early surgical outcomes of MVR in patients with history of CMV to see whether their disease behaves differently, when compared with patients without prior CMV undergoing MVR.

Methods: This single center retrospective cohort study was conducted in Sree Chitra Tirunal Institute for Medical Sciences and Technology, Thiruvananthapuram, Kerala, India. Patients who underwent MVR from January 2008 to December 2012 at our institute were studied. The hospital records of 90 patients were analyzed both in the CMV cohort and also in the non-CMV cohort. Preoperative details, intraoperative parameters, immediate postsurgery echocardiography parameters, and follow-up echocardiography details at 1 year and 5 years were studied.

Results: Both the cohorts were similar in age, height, weight, and BSA. In the CMV cohort, $67 \%$ were females and in the non-CMV cohort $48 \%$ were females. Most of the patients in both the cohorts presented with functional classes 2 and 3 . The mean duration between onset of symptoms and MVR in the CMV cohort and the non-CMV cohort was 24.6 years and 6.25 years, respectively. Fifty-nine patients in the CMV cohort had preoperative atrial fibrillation, whereas 47 patients in the non-CMV cohort presented with atrial fibrillation. The mean left atrial (LA) size of patients with sinus rhythm and atrial fibrillation was 46.34 (SE, 0.852) and 55.21(SE, 0.808), respectively. Preoperative echocardiographic assessment revealed a mean ejection fraction of $62 \%$ and $63 \%$, mean mitral stenosis gradient of $13 \mathrm{~mm} \mathrm{Hg}$ and $14.7 \mathrm{~mm} \mathrm{Hg}$, mean LA size of $53.2 \mathrm{~mm}$ and $50.5 \mathrm{~mm}$, and mean right ventricular systolic pressure of $47.5 \mathrm{~mm} \mathrm{Hg}$ and

Received November 11, 2018; accepted February 6, 2019.

Correspondence: Bineesh K. Radhakrishnan, Assistant professor, Department of CVTS, Sree Chitra Tirunal Institute for Medical Sciences and Technology, Thiruvananthapuram, Kerala 695011, India; +91-9497017919; fax: +91(0)471-2446433 (e-mail: bineeshkrishna@gmail.com).
$43.6 \mathrm{~mm} \mathrm{Hg}$ in the post-CMV cohort and in the non-CMV cohort, respectively. The CMV cohort had a longer cardiopulmonary bypass time (111.5 minutes) in comparison with the non-CMV cohort (97 minutes). The aortic cross-clamp time remained similar in both the cohorts. Thirty-six percent of the post-CMV cohort patients had a valve size of 25 , and $48 \%$ of patients belonging to the non-CMV cohort had a valve size of 27 . The percent of moderate-to-severe subvalvar pathology was 88 in both the cohorts. Patients belonging to the post-CMV cohort had a median ventilation time of 16.35 hours, and the patients of the non-CMV cohort had a median ventilation time of 13.75 hours. The duration of ICU stay was 4.41 (SE, 0.188) days and 4.13 (SE, 0.153) days, and length of hospital stay was 8.93 (SE, 0.230) days and 9.13 (SE, 0.313 ) days in the CMV and the non-CMV cohorts, respectively. Inotropic requirement, measured by the vasoactive inotropic score, was higher in the post-CMV group (11.9), when compared to the other cohort (9.7). Right ventricular (RV) function and pulmonary arterial hypertension assessed in the immediate postoperative period, at 1 year, and at 5 years did not show any significant difference.

Conclusion: The percentage of females in the CMV cohort is higher. Delaying the valve replacement by performing a surgical palliative procedure like $\mathrm{CMV}$, is beneficial in female patients in the child-bearing age group so that they can complete the families. The disease process started earlier in the CMV cohort, and they had a longer duration of illness before undergoing MVR. Even with the longer duration of disease, the RV function, LA size, PA pressures, and mitral stenosis gradients were comparable. Therefore, CMV prevented progression of the disease in the CMV group. The mean LA size is significantly higher in patients with atrial fibrillation. The CMV cohort had a longer cardiopulmonary bypass time. The duration of ventilation, ICU stay, and hospital stay were similar in both cohorts. Inotrope requirement was higher in the post-CMV group. RV function and pulmonary arterial hypertension assessed in the immediate postoperative period, at 1 year, and at 5 years did not show any significant difference.

\section{INTRODUCTION}

The incidence of rheumatic fever and rheumatic heart disease still remains high in the developing countries 


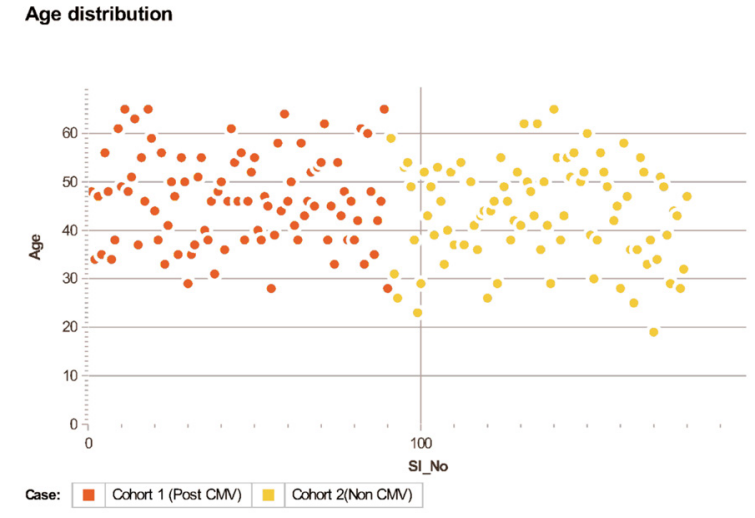

Figure 1. Age distribution. SI_No, serial number.

[McLaren 1994; Carapetis 2007]. Mitral stenosis is predominantly due to rheumatic origin and affects females more than males [Manjunath 2014]. Mitral stenosis develops over decades, but evolves quite rapidly leading to significant pulmonary hypertension and congestive cardiac failure in people in developing countries in comparison to people in developed countries. [Tadele 2013; Maeder 2018; Shah 2018]. Historically, closed mitral valvotomy (CMV) was the first effective intervention for mitral stenosis that provided patients with hemodynamic and clinical improvement. The first successful CMV was reported as early as 1923 by Cutler and Levine, and this was followed by a report by Souttar in 1925 [Souttar 1925]. It provides a significant symptomfree period as established by a number of studies [Ellis 1973; Brock 1975]. However, rheumatic heart disease is a progressive disease leading to mitral restenosis, and a majority of these patients require a second intervention in the form of closed or open valvotomy or valve replacement [Suzuki 1993]. This subset of patients who present for mitral valve replacement (MVR) eventually after CMV represents a unique group in comparison with those who are scheduled for valve replacement without prior CMV. The uniqueness is that the former group has a longer period of disease despite being symptom free. We studied the intraoperative features and the immediate and early surgical outcomes of MVR in this particular subset of patients to see whether their disease behaves differently, when compared with patients without prior CMV undergoing MVR.

\section{MATERIALS AND METHODS}

This single center retrospective cohort study was conducted in Sree Chitra Tirunal Institute for Medical Sciences and Technology, Thiruvananthapuram, Kerala, India, between March and June 2018. Institutional ethics committee clearance was obtained. The outcomes of MVR in patients with history of CMV was compared to patients who did not undergo CMV prior to MVR. Patients who underwent MVR from January 2008 to December 2012 at our institute were studied.
Table 1. Demographic Details

\begin{tabular}{lccc}
\hline & $\begin{array}{c}\text { Exposed Cohort } \\
\text { (Post-CMV), } \mathrm{n}=90\end{array}$ & $\begin{array}{c}\text { Unexposed } \\
\text { Cohort, } \mathrm{n}=90\end{array}$ & $P$ \\
\hline $\begin{array}{l}\text { Age at the time of MVR } \\
\text { (years) }\end{array}$ & 46.36 & 43.87 & .088 \\
Height $(\mathrm{cm})$ & 155.27 & 157.08 & .185 \\
Weight $(\mathrm{kg})$ & 53.933 & 54.278 & .821 \\
BSA $\left(\mathrm{kg} / \mathrm{m}^{2}\right)$ & 1.51 & 1.53 & \\
Females & 61 & 46 & .03
\end{tabular}

\section{Primary Objective}

The primary objective was to compare the immediate and early postoperative outcomes of MVR in patients with and without history of CMV.

\section{Secondary Objective}

The secondary objective was to study the changes in right ventricular (RV) function and pulmonary artery (PA) hypertension in patients with and without history of CMV who underwent MVR.

\section{Inclusion Criteria}

All patients who underwent MVR between 2008 and 2012 with a previous history of CMV were considered as the exposed group (cohort 1), and those who underwent MVR without antecedent CMV were included in the unexposed group (cohort 2).

\section{Exclusion Criteria}

Patients with history of prior balloon mitral valvotomy, open mitral commissurotomy, those who underwent redo MVR, and patients in whom other cardiac surgical procedures such as coronary artery bypass grafting were done at the time of MVR were excluded from our study.

\section{Methods}

One hundred and four patients satisfied the inclusion criteria for the CMV cohort and, their records were followed up. Twelve among them were lost to follow-up, and 2 patients died because of myocardial dysfunction in the immediate postoperative period; the hospital records of 90 patients were analyzed in the CMV cohort. The same number $(n=90)$ of patients were included in the non-CMV cohort by simple random sampling (unexposed cohort). Data were collected by using a semistructured questionnaire from hospital records. Preoperative details including demographics, duration of disease, and echocardiography parameters, intraoperative parameters such as aortic cross-clamp (ACC) time, cardiopulmonary bypass $(\mathrm{CPB})$ time, and valve size, subvalvar pathology, postoperative parameters such as duration of ventilation, intensive care unit (ICU) and hospital stays, inotrope requirement, immediate postsurgery echocardiography parameters, and follow-up echocardiography details at 1 year and 5 years were collected from hospital records. 


\section{GENDER}

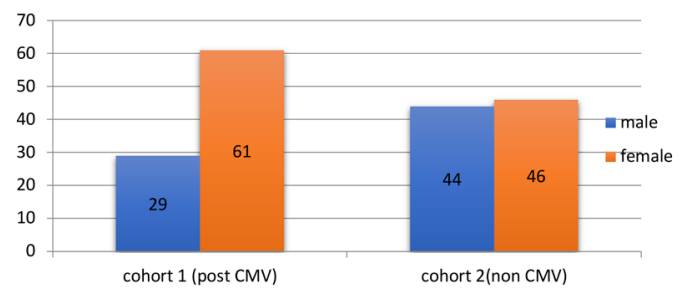

Figure 2. Gender distribution.

\section{Statistical Analysis}

Quantitative data were analyzed to indicate mean \pm standard deviation. Parametric variables were evaluated with $\mathrm{t}$ test; and nonparametric variables, with chi-square and MannWhitney $U$ test.

\section{Outcome Parameters}

Preoperative demographic parameters, functional class, rhythm, disease duration, time period from CMV to MVR, echocardiographic parameters, intraoperative surgical details, inotropic support, duration of mechanical ventilation, length of ICU stay and hospital stay, postoperative echocardiography details at the time of discharge and at 1 year and 5 years were obtained from the hospital records.

\section{Definitions}

Persistent pulmonary hypertension (PPH) was diagnosed if systolic pulmonary artery pressure (sPAP) estimated by Doppler echocardiography was more than $40 \mathrm{~mm} \mathrm{Hg}$ [Hoeper 2013; Chemla 2015].

$\mathrm{RV}$ dysfunction was defined by either RV end-diastolic diameter $>41 \mathrm{~mm}$ (base) and $>35 \mathrm{~mm}$ (midlevel) or RV hypokinesia or tricuspid annulus plane systolic excursion (TAPSE) as defined as the total excursion of the tricuspid annulus from tele-diastole to end-systole less than $16 \mathrm{~mm}$ or dilation of the right ventricle (more than two thirds of the left ventricle in its transversal diameter). Other criteria included paradoxical septal wall motion, pulmonary hypertension, and severe tricuspid regurgitation [Rudski 2010; Kossaify 2015].

\section{Calculated Parameters}

Vasoactive inotropic score [Gaies 2014] was calculated by using this formula: dopamine dose $(\mu \mathrm{g} / \mathrm{kg}$ per min $)+$ dobutamine dose $(\mu \mathrm{g} / \mathrm{kg}$ per min $)+100 \times$ epinephrine dose $(\mu \mathrm{g} /$ $\mathrm{kg}$ per min $)+10 \times$ milrinone dose $(\mu \mathrm{g} / \mathrm{kg}$ per $\mathrm{min})+10,000$ $\times$ vasopressin dose (units $/ \mathrm{kg}$ per min) $+100 \times$ norepinephrine dose $(\mu \mathrm{g} / \mathrm{kg}$ per min).

\section{RESULTS}

\section{Demographic Details And Functional Class}

Both the cohorts were similar in age (Figure 1), height, weight, and body surface area (BSA). In the CMV cohort,
Table 2. NYHA Functional Class

\begin{tabular}{lcc}
\hline NYHA Functional Class & $\begin{array}{c}\text { Exposed Cohort } \\
\text { (Post-CMV), } \mathrm{n}=90\end{array}$ & $\begin{array}{c}\text { Unexposed Cohort, } \\
\mathrm{n}=90\end{array}$ \\
\hline 1 & 0 & 1 \\
2 & 44 & 48 \\
3 & 38 & 40 \\
4 & 8 & 1
\end{tabular}

$67 \%$ were female (Figure 2), and in the non-CMV cohort, $48 \%$ were female (Table 1$)$.

Most of the patients presented with functional classes 2 and 3 in both the cohorts, prior to surgery (Table 2).

In the CMV cohort, the mean duration between onset of disease and time of undergoing CMV was 4.30 years (standard error of the mean [SEM], 0.432), and the mean duration between CMV and time of undergoing MVR was 20.38 years (SEM, 0.781). The mean age at which MVR was done in the CMV cohort was 46.3 years.

In the non-CMV cohort, the mean duration of onset of symptoms to time of MVR was 6.250 years (SEM, 0.6388). The mean age at which MVR was done in the non-CMV cohort was 43.87 years. The disease process started earlier in the CMV cohort, and its members had a longer duration of illness before undergoing MVR.

\section{Rbythm}

Fifty-nine patients in the CMV cohort had preoperative atrial fibrillation, whereas 47 patients in the non-CMV cohort presented with atrial fibrillation (Table 3). Atrial fibrillation persisted postoperatively and at 1 - and 5-year follow-ups, in the patients who had it preoperatively. One patient in the unexposed cohort had complete heart block, which required pacemaker insertion.

The mean left atrial (LA) size is significantly higher in patients with atrial fibrillation with a $P$ value <.001 (Table 4).

\section{Echocardiographic Features}

Preoperative echocardiographic assessment revealed a mean ejection fraction of $62 \%$ and $63 \%$, mean mitral stenosis gradient of $13 \mathrm{~mm} \mathrm{Hg}$ and $14.7 \mathrm{~mm} \mathrm{Hg}$, mean LA size of $53.2 \mathrm{~mm}$ and $50.5 \mathrm{~mm}$, and mean right ventricular systolic pressure (RVSP) of $47.5 \mathrm{~mm} \mathrm{Hg}$ and $43.6 \mathrm{~mm}$ $\mathrm{Hg}$ in the post-CMV cohort and in the non-CMV cohorts, respectively. Both cohorts had patients with similar ventricular function, LA size, mitral valve gradients, and pulmonary arterial hypertension. More than $87 \%$ of the patients in both the cohorts had good RV function in the preoperative period.

\section{Operative Time}

The CMV cohort had a longer CPB time (111.5 minutes) in comparison with the non-CMV cohort (97 minutes), and this difference is statistically significant. The aortic crossclamp time remained similar in both the cohorts. 


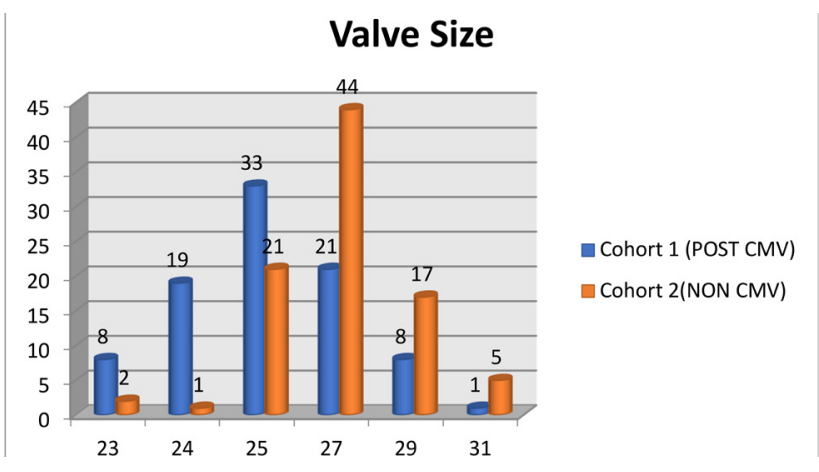

Figure 3. Valve size.

\section{Type of Prosthesis}

Thirty-six percent of the post-CMV cohort patients had a valve size of 25 , and $48 \%$ of patients belonging to the nonCMV cohort had a valve size of 27 (Figure 3), and this difference is not clinically and statistically significant. Sixtyfive patients in the post-CMV cohort and 67 patients in the non-CMV cohort received St. Jude mechanical valve prosthesis. Twenty-two patients in the post-CMV cohort and 20 patients from the non-CMV cohort received the TTK Chitra heart valve prosthesis (from Sree Chitra Tirunal Institute for Medical Sciences and Technology). Only 1 patient received a bioprosthetic valve.

\section{Surgical Findings}

The percent of moderate-to-severe subvalvar pathology was 88 in both the cohorts.

\section{Additional Surgical Procedures}

Along with MVR, 13 patients underwent tricuspid valve annuloplasty, and 4 patients underwent tricuspid valve bicuspidization. Two patients underwent RF ablation. No patients had maze procedures. LA plication was done in 16 patients; LA clot removal, in 19 patients; and LA appendage exclusion, in 38 patients.

\section{Mechanical Ventilation Time and ICU Stay}

Patients belonging to the post-CMV cohort had a median ventilation time of 16.35 hours, and the patients of the nonCMV cohort had a median ventilation time of 13.75 hours, and the difference is not statistically significant. The duration of ICU stay of 4.41 (SE, 0.188) days and 4.13 (SE, 0.153) days and the length of hospital stay of 8.93 (SE, 0.230) days and 9.13 (SE, 0.313) days are comparable in the CMV and the non-CMV cohorts.

Inotropic requirement, measured by the vasoactive inotropic score, was higher in the post-CMV group (11.9) when compared to the other cohort (9.7). Independent samples test value $=2.064 ; P=.040$.

\section{Mortality}

Out of the 104 patients studied in the post-CMV cohort, 2 patients died within 30 days of surgery because of myocardial dysfunction. There was no mortality in the non-CMV
Table 3. Preoperative Rhythm

\begin{tabular}{lcc}
\hline & $\begin{array}{c}\text { Exposed Cohort } \\
\text { (Post-CMV) }\end{array}$ & Unexposed Cohort \\
\hline Sinus rhythm & 30 & 41 \\
Atrial fibrillation & 59 & 47 \\
Paroxysmal atrial fibrillation & 1 & 1 \\
Complete heart block & 0 & 1
\end{tabular}

Table. 4. Atrial Fibrillation and LA Size

\begin{tabular}{lcc} 
& No. of Patients & Mean LA Size (mm) \\
\hline Sinus rhythm & 71 & 46.34 (SE, 0.852) \\
Atrial fibrillation & 108 & 55.21 (SE, 0.808)
\end{tabular}

cohort. There were no other deaths in either cohort within 5 years of surgery.

\section{Right Ventricular Function and Pulmonary Arterial Hypertension}

RV function and pulmonary arterial hypertension assessed in the immediate postoperative period, at 1 year, and at 5 years did not show any significant difference (Figures 4A, 4B).

\section{DISCUSSION}

Both the cohorts had patients with similar age, height, weight, and BSA. The mean age at the time of MVR in the post-CMV cohort was 46.36 years and in the non-CMV cohort was 43.87 years. Mean height was $155.27 \mathrm{~cm}$ and $157.08 \mathrm{~cm}$, respectively. Mean weight was $53.933 \mathrm{~kg}$ and $54.278 \mathrm{~kg}$, respectively. Mean BSA $\left(\mathrm{kg} / \mathrm{m}^{2}\right)$ was 1.51 and 1.53 , respectively.

In the CMV cohort, $67 \%$ were female, and in the nonCMV cohort, $48 \%$ were female. The percentage of females in the CMV cohort is higher, and this difference is statistically significant. In a single center study of 13,289 patients by C.N. Manjunath et al, $60.2 \%$ patients in the rheumatic group had mitral valve involvement, of whom mitral stenosis was present in $72.8 \%$. More than two thirds $(65.9 \%)$ of mitral stenosis patients were female [Manjunath 2014]. In a single center study of 126 pregnant women with rheumatic mitral stenosis, CMV improved the functional class to 1 or 2 in $86 \%$ of the women, at 5 years after the procedure [Pavankumar 1988]. The restenosis rate was $2 \%$ per year in these women, which is acceptable. Delaying the valve replacement by performing a surgical palliative procedure such as CMV is beneficial in female patients in the child-bearing age group so that they can complete their families.

In the CMV cohort, the mean duration between onset of disease and time of undergoing CMV was 4.30 years (SEM, 0.432 ), and the mean duration between $\mathrm{CMV}$ and time 

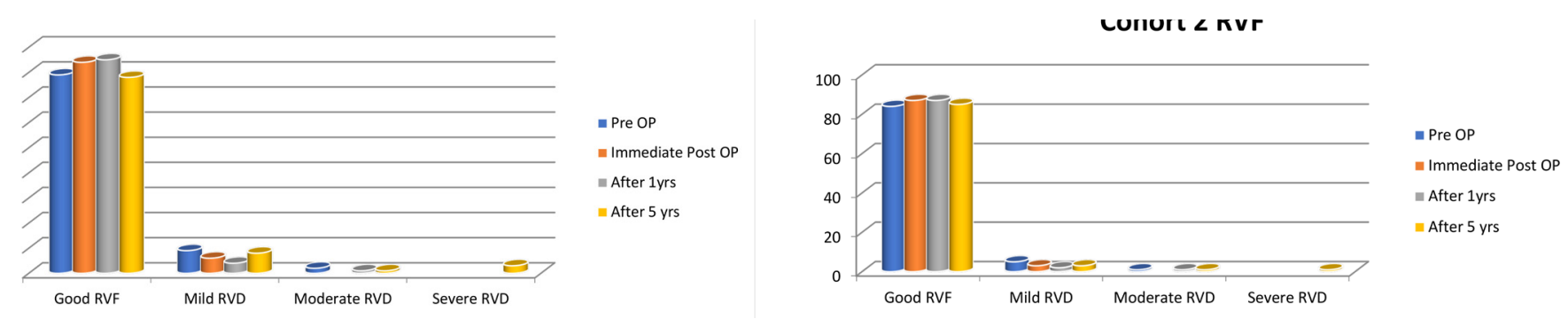

Figure 4. (A), RV function in the immediate postoperative period, at 1 year, and at 5 years in the post-CMV cohort. (B), RV function in the immediate postoperative period, at 1 year, and at 5 years in the non-CMV cohort. RVF, RV function; RVD, RV dysfunction.

Table 5. Preoperative Transthoracic Echocardiography*

\begin{tabular}{lcc}
\hline $\begin{array}{l}\text { Preoperative Transtho- } \\
\text { racic Echocardiography }\end{array}$ & $\begin{array}{c}\text { Exposed Cohort } \\
\text { (Post-CMV), } \mathrm{n}=90\end{array}$ & $\begin{array}{c}\text { Unexposed Cohort, } \\
\mathrm{n}=90\end{array}$ \\
\hline Ejection fraction (\%) & $\begin{array}{c}62.41(\mathrm{SE}, 0.936) \\
(\min 36 \text { to } \max 87)\end{array}$ & $\begin{array}{c}63.14(\mathrm{SE}, 0.874) \\
(\min 37 \text { to } \max 87)\end{array}$ \\
Mitral stenosis mean & $13.11(\mathrm{SE}, 0.510)$ & $14.76(\mathrm{SE}, 0.609)$ \\
gradient $(\mathrm{mm} \mathrm{Hg})$ & $(\min 4$ to $\max 30)$ & $(\min 3$ to $\max 30)$ \\
LA size & $53.22(\mathrm{SE}, 1.407)$ & $50.50(\mathrm{SE}, 0.893)$ \\
& $(\min 30$ to $\max 110)$ & $(\min 30$ to max 70) \\
RVSP & $47.93(\mathrm{SE}, 2.138)$ & $43.62(\mathrm{SE}, 2.812)$ \\
& $(\min 0$ to $\max 110)$ & $(\min 0$ to $\max 130)$ \\
\hline
\end{tabular}

*Min, minimum; max, maximum.

of undergoing MVR was 20.38 years (SEM, 0.781). In the non-CMV cohort, the mean duration of onset of symptoms to time of MVR was 6.250 years (SEM, 0.6388). The mean age at which MVR was done in the CMV cohort was 46.3 years and in the non-CMV cohort was 43.87 years. The patients in the CMV cohort had an earlier onset of disease and longer duration of illness before undergoing MVR. The mean duration between onset of symptoms and MVR in the CMV cohort and the non-CMV cohort was 24.6 years and 6.25 years, respectively. This is attributed to the symptomfree period following CMV.

The prevalence of atrial fibrillation and preoperative echocardiographic parameters were similar in both the cohorts. Fifty-nine patients in the CMV cohort had preoperative atrial fibrillation, whereas 47 patients in the non-CMV cohort presented with atrial fibrillation.

The mean LA size was similar in both the cohorts, 53.22 $\mathrm{mm}$ (SE, 1.407) in the CMV cohort and $50.50 \mathrm{~mm}$ (SE, 0.893 ) in the non-CMV cohort, despite the disease process being longer in the CMV cohort.

The mean LA size of patients with sinus rhythm and atrial fibrillation were 46.34 (SE, 0.852) and 55.21 (SE, 0.808), respectively. The mean LA size is significantly higher in patients with atrial fibrillation with a $\mathrm{P}$ value <.001. Atrial fibrillation is a common occurrence in mitral stenosis due to LA enlargement [Kim 2015]. According to R. Mariyamballi et al, out of 42 patients with mitral stenosis and LA size
Table. 6. Inotropic Score

\begin{tabular}{lc}
\hline lonotropic score & Mean \\
\hline Cohort 1 (post-CMV) & $11.972(\mathrm{SE}, 0.9843)$ \\
Cohort 2 (non-CMV) & $9.572(\mathrm{SE}, 0.6192)$
\end{tabular}

$>40 \mathrm{~mm}, 29$ patients $(93.55 \%)$ were in atrial fibrillation, and only $13(68.42 \%)$ were in sinus rhythm, whereas among the 8 patients with LA size less than $40 \mathrm{~mm}$, only 2 were in atrial fibrillation, and 6 were in sinus rhythm [Mariyamballi 2016].

Mean ejection fraction was $62.41 \%$ and $63.14 \%$; mean mitral stenosis mean gradient was 13.11 (SE, 0.510) $\mathrm{mm} \mathrm{Hg}$ and 14.76 (SE, 0.609) $\mathrm{mm} \mathrm{Hg}$; and mean RVSP value was 47.93 (SE, 2.138) and 43.62 (SE, 2.812), respectively in the CMV and non-CMV groups, More than $87 \%$ of the patients in both the cohorts of disease, the RV function, LA size, PA pressures, and mitral stenosis gradients were comparable. Therefore, CMV prevented progression of the disease in the CMV group.

The CMV cohort had a longer CPB time (111.5 minutes) in comparison with the non-CMV cohort (97 minutes), which is statistically significant and is due to the longer time needed for releasing the adhesions between the heart and pericardium in the post-CMV patients. However, the aortic cross-clamp time is similar in both the cohorts.

Patients belonging to the post-CMV cohort had a median ventilation time of 16.35 hours, and the patients of the nonCMV cohort had a median ventilation time of 13.75 hours, and the difference is not statistically significant. The duration of ICU stay was 4.41 (SE, 0.188) days and 4.13 (SE, 0.153) days, and length of hospital stay was 8.93 (SE, 0.230) days and 9.13 (SE, 0.313) days in the CMV and the non-CMV cohorts. The duration of ICU stay and hospital stay were similar in both cohorts.

Inotropic requirement, measured by the vasoactive inotropic score, was higher in the post-CMV group (11.9) when compared to the other cohort (9.7), and it is statistically significant.

In the post-CMV cohort, $36 \%$ of the patients had a valve size of 25 , and $48 \%$ of patients belonging to the non-CMV cohort had a valve size of 27 , and this difference is not clinically and statistically significant. RV function and pulmonary arterial hypertension assessed in the immediate postoperative 
period, at 1 year, and at 5 years showed similar progression in both cohorts.

\section{CONCLUSION}

The percentage of females in the CMV cohort is higher, and this difference is statistically significant. Delaying the valve replacement by performing a surgical palliative procedure such as CMV is beneficial in female patients in the childbearing age group so that they can complete their families. The disease process started earlier in the CMV cohort, and they had a longer duration of illness before undergoing MVR. Despite the longer duration of disease, the RV function, LA size, PA pressures, and mitral stenosis gradients were comparable. Thus, closed valvotomy prevented progression of the disease in the CMV group. The mean LA size is significantly higher in patients with atrial fibrillation $(P<.001)$. The CMV cohort had a longer CPB time but comparable aortic crossclamp time. However, the duration of mechanical ventilation, ICU stay, and hospital stay were similar in both cohorts. Inotrope requirement was higher in the post-CMV group. RV function and pulmonary arterial hypertension assessed in the immediate postoperative period, at 1 year, and at 5 years did not show any significant difference.

\section{REFERENCES}

Brock R. 1975. Long-term results after closed mitral valvotomy. Isr J Med Sci 11:122-9.

Carapetis JR. 2007. Rheumatic heart disease in developing countries. N Engl J Med 357:439-41.

Chemla D, Humbert M, Sitbon O, Montani D, Hervé P. 2015. Systolic and mean pulmonary artery pressures: are they interchangeable in patients with pulmonary hypertension? Chest 147:943-50.

Ellis LB, Singh JB, Morales DD, Harken DE. 1973. Fifteen-to-twentyyear study of one thousand patients undergoing closed mitral valvuloplasty. Circulation 48:357-64.

Gaies MG, Jeffries HE, Niebler RA, et al. 2014. Vasoactive-inotropic score is associated with outcome after infant cardiac surgery: an analysis from the Pediatric Cardiac Critical Care Consortium and Virtual PICU System Registries. Pediatr Crit Care Med;15:529-37.
Hoeper MM, Bogaard HJ, Condliffe R, et al. 2013. Definitions and diagnosis of pulmonary hypertension. J Am Coll Cardiol 62(25 suppl):D42-50.

Kim HJ, Cho GY, Kim YJ, et al. 2015. Development of atrial fibrillation in patients with rheumatic mitral valve disease in sinus rhythm. Int J Cardiovasc Imaging 31:735-42.

Kossaify A. 2015. Echocardiographic assessment of the right ventricle, from the conventional approach to speckle tracking and three-dimensional imaging, and insights into the "right way" to explore the forgotten chamber. Clin Med Insights Cardiol 9:65-75.

Maeder MT, Weber L, Buser M, et al. 2018. Pulmonary hypertension in aortic and mitral valve disease. Front Cardiovasc Med 5:40.

Manjunath CN, Srinivas P, Ravindranath KS, Dhanalakshmi C. 2014. Incidence and patterns of valvular heart disease in a tertiary care high-volume cardiac center: a single center experience. Indian Heart J 66:320-6.

Mariyamballi R, Thimmappa N, Bindumathi PL, Pillai P, Balasundaram B. 2016. Correlation of left atrial size and atrial fibrillation in RHD with mitral valve disease. J Evolution Med Dent Sci 5:978-81.

McLaren MJ, Markowitz M, Gerber MA. 1994. Rheumatic heart disease in developing countries: the consequence of inadequate prevention. Ann Intern Med 120:243-5.

Pavankumar P, Venugopal P, Kaul U, et al. 1988. Closed mitral valvotomy during pregnancy: a 20-year experience. Scand J Thorac Cardiovasc Surg 22:11-5.

Rudski LG, Lai WW, Afilalo J, et al. 2010. Guidelines for the echocardiographic assessment of the right heart in adults: a report from the American Society of Echocardiography: endorsed by the European Association of Echocardiography, a registered branch of the European Society of Cardiology, and the Canadian Society of Echocardiography. J Am Soc Echocardiogr 23:685-713; quiz 786-8.

Shah SN, Sharma S. Mitral stenosis. [updated 2018 Oct 27; accessed 2018 Mar 5]. In: StatPearls [internet]. Treasure Island (FL): StatPearls Publishing; 2018 Jan- . Available from: https://www.ncbi.nlm.nih.gov/ books/NBK430742/.

Souttar HS. 1925. The surgical treatment of mitral stenosis. Br Med J 2:603-6.

Suzuki S, Kondo J, Imoto K, et al. 1993. [Long-term results of closed mitral commissurotomy--comparative study of closed mitral commissurotomy, open mitral commissurotomy and mitral valve replacement]. Nihon Kyobu Geka Gakkai Zasshi 41(9):1460-6. Japanese.

Tadele H, Mekonnen W, Tefera E. 2013. Rheumatic mitral stenosis in children: more accelerated course in sub-Saharan patients. BMC Cardiovasc Disord 13:95. 